\title{
Energy Storage System for DC Electrified Railway Using EDLC
}

\author{
Takeshi KONISHI \\ Researcher, \\ Shin-ichi HASE \\ Power Supply Systems, Power Supply Technology Div.

\section{Yoshinobu NAKAMICHI} \\ General Manager, \\ Power Supply Technology Div.
}

\begin{abstract}
How to stabilize power sources to minimize voltage drops, power load fluctuations, and regenerative power lapses has been a key problem area in DC feeding circuits. Energy storage media that use power efficiently and eradicate such problems have been attracting interest, with several energy storage applications, including batteries and flywheels, having already been investigated. A wide range of large-scale electric double-layer capacitors (EDLCs) quickly charged and discharged, offer durability, maintenance-free features, low pollution and high efficiency levels, have been developed. Our research compared batteries with EDLCs in terms of their ability to charge/discharge at DC $75 \mathrm{~V}$. For the latest study, we produced a prototype DC electrified railway energy storage system that consists of EDLCs, a diode bridge rectifier, a chopper system, and a pulse width modulated (PWM) converter, useful information being obtained from charge/discharge tests. This paper describes the characteristics and results of the energy storage system experiments.
\end{abstract}

Keywords: energy storage systems, electric double-layer capacitors, chopper system, DC electrified railway

\section{Introduction}

In DC electrified railway systems, power is supplied from substations to railway vehicles via feeding lines and the rails. When substation-train distances and power demands are great, large amounts of current flow from substations to trains only for the voltage drops to be greatly reduced by the time it reaches a train due to the resistance of the feeding line. If there were energy storage systems located nearer the trains, there would be less need for current supplied from substations and voltage drops and power fluctuations would also be reduced. The regenerative power of the trains would also be effectively utilized without power lapses occurring because the power would be absorbed by the energy storage system. In cases where the two substations are far apart and it is deemed too difficult to install a new substation, it would be more effective to install an energy storage system between them.

Recent years have witnessed remarkable advances in energy storage media technology, with a wide range of EDLCs having been rapidly developed ${ }^{1) \sim 3)}$. These feature quicker charge/discharge characteristics than secondary batteries, low pollution, high efficiency, and lowmaintenance durability. We carried out fundamental tests on each energy storage medium as well as a hybrid system rated at DC $75 \mathrm{~V}$. For the latest study, a prototype of an energy storage system for a DC $400 \mathrm{~V}$ electrified railway model has been produced. This consists of EDLCs for energy storage, a step-up and -down chopper system to regulate charge/discharge, a diode bridge rectifier to simulate a substation, and a PWM converter that corre- sponds to a railway vehicle. Charge/discharge tests of the prototype were carried out to verify that it could contribute to stable power supply for DC electrified railways.

\section{Electric double layer capacitors}

If the electrodes of an electrolytic capacitor are dipped into an electrolyte, thin insulated layers form in the electrolyte that is in contact with the electrodes. As a result, two pairs of what are known as electric double layers are formed between the electrode and the insulated layer. If the applied voltage is lower than the minimum voltage that electrolyzes the electrolyte, the layers are maintained and the gap between them is extremely thin, so that a large amount of energy can be stored.
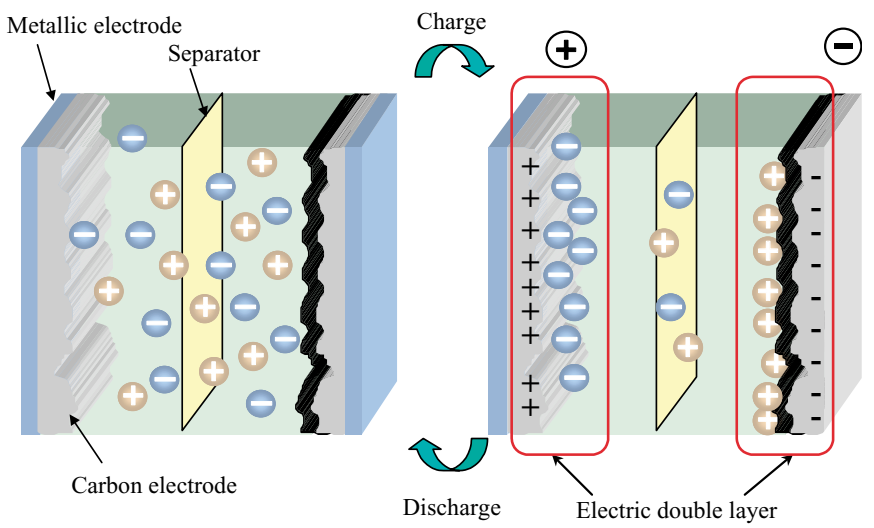

Fig. 1 Structure of electric double-layer capacitor 
The structure of an electric double-layer capacitor is shown in Fig. 1. The electrolyte constitutes the two layers and a middle layer. Porous carbon is used so that the electrodes offer a large surface area, and organic liquid often used as an electrolyte.

The general equivalent circuit of an electric doublelayer capacitor is indicated with a capacitance $(C)$ and a resistance $(R)$ connected in series. This is a good approximation of any real capacitor if long-term processes are excluded ${ }^{4)}$. The terminal voltage of the capacitors $v$ and the charge/discharge current of the capacitors $i$ can be expressed by the following equation ${ }^{4)}$.

$$
v+\frac{1}{C} \int i d t+R i=0
$$

The equation illustrates the fundamental fact that increases in the charge/discharge current mean increases in the value of $R i$. This situation causes not only increased energy loss but also a small usable amount of terminal voltage. When electric double-layer capacitors are applied to high power energy storage systems, therefore, techniques to increase the capacitance and reduce the inner resistance are required.

\section{Fundamental tests at DC $75 \mathrm{~V}$}

Fundamental tests were carried out on a DC $75 \mathrm{~V}$ system as a preliminary study into an energy storage system using EDLCs, lead batteries and lithium batteries. The details of the tests are described in the following paragraphs.

\subsection{Energy storage media}

The energy storage media used for the fundamental tests of a DC $75 \mathrm{~V}$ hybrid system were two kinds of batteries and an EDLC. Tables 1 and 2 indicate the specifications of the media, all of which were initially charged

Table 1 Composition of batteries for $75 \mathrm{~V}$ test

\begin{tabular}{ccc}
\hline Item & Lead battery & Lithium battery \\
\hline Composition & 38 -series & 19 -series \\
\hline Voltage & $76 \mathrm{~V}$ & $76 \mathrm{~V}$ \\
\hline Current & $250 \mathrm{Ah}$ & $40 \mathrm{Ah}$ \\
\hline Dimensions & D440 W1850 H450 mm & W600 D700 H1085 mm \\
\hline Weight & $1000 \mathrm{~kg}$ & $100 \mathrm{~kg}$ \\
\hline
\end{tabular}

Table 2 Composition of EDLCs for 75V test

\begin{tabular}{ccc}
\hline Item & Unit & Block \\
\hline Composition & 46 cells in series & 6 units in parallel \\
\hline Voltage & $93 \mathrm{~V}$ & $93 \mathrm{~V}$ \\
\hline Current & $50 \mathrm{~A}$ & $300 \mathrm{~A}$ \\
\hline Capacity & $9.5 \mathrm{~F}$ & $57 \mathrm{~F}$ \\
\hline Resistance & $0.58 \Omega$ & $0.1 \Omega$ \\
\hline Dimensions & D340 W340 H50 mm & D431 W465 H537 mm \\
\hline Weight & $7.2 \mathrm{~kg}$ & $60 \mathrm{~kg}$ \\
\hline
\end{tabular}

to $\mathrm{DC} 75 \mathrm{~V}$.

\subsection{Test circuit}

The DC $75 \mathrm{~V}$ test circuit is shown in Fig. 2. A DC constant voltage was supplied to a substation model and a DC electronic resistive load for a railway vehicle model. Two resistances to simulate feeding impedance were set.

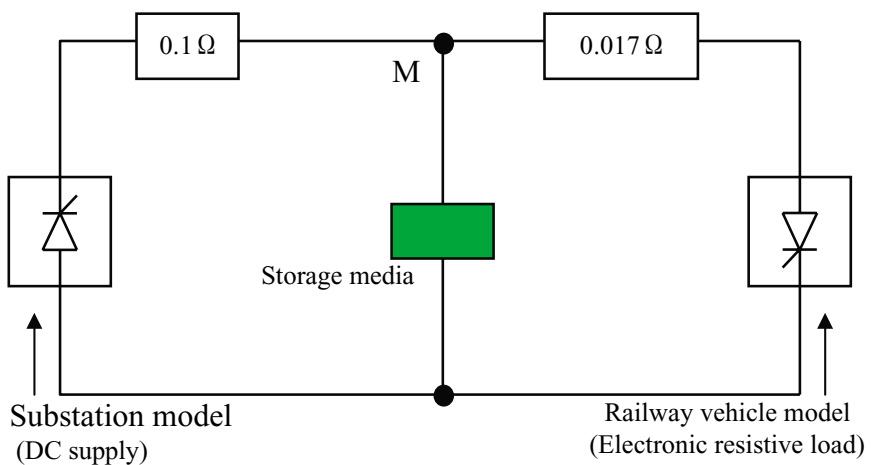

Fig. 2 DC $75 \mathrm{~V}$ system test circuit

\subsection{Load pattern}

The two waveforms shown in Fig. 3 were applied as the railway vehicle load patterns. That shown in (a) is the "VVVF pattern," which simulates railway vehicles equipped with a variable voltage, variable frequency (VVVF) inverter. The load current increased linearly until it reached its peak. The other is the "rheostat control type," which simulates series-parallel control of a DC motor. In this case, the load current increased rapidly.

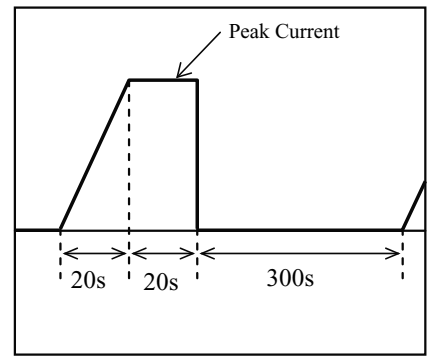

(a) VVVF pattern

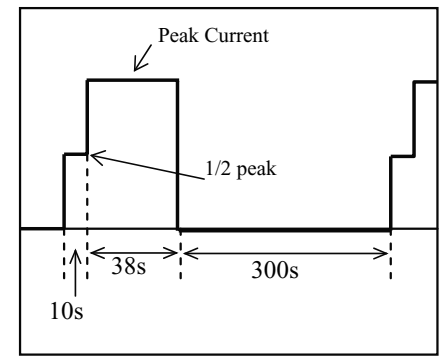

(b) Rheostat control pattern
Fig. 3 DC $75 \mathrm{~V}$ system load pattern

\subsection{Test results}

\subsubsection{Without storage media}

Tests of the two patterns were carried out first without storage media being used. The peak current was set at either $200 \mathrm{~A}$ or $600 \mathrm{~A}$. The voltage characteristics at the M-point are shown in Fig. 4.

From the test results, the minimum voltage at the M-point was uniquely determined by the peak load current regardless of the waveform. The voltage dropped to $46 \mathrm{~V}$ at a maximum of $200 \mathrm{~A}$ and $16 \mathrm{~V}$ at a maximum of $600 \mathrm{~A}$. On the other hand, when the voltage at the electronic resistive load dropped to less than $6 \mathrm{~V}$ at a maximum of $600 \mathrm{~A}$, it was impossible to maintain the function of the load because of low voltage. The voltage at the Mpoint returned to zero by the functional stop of the load. 


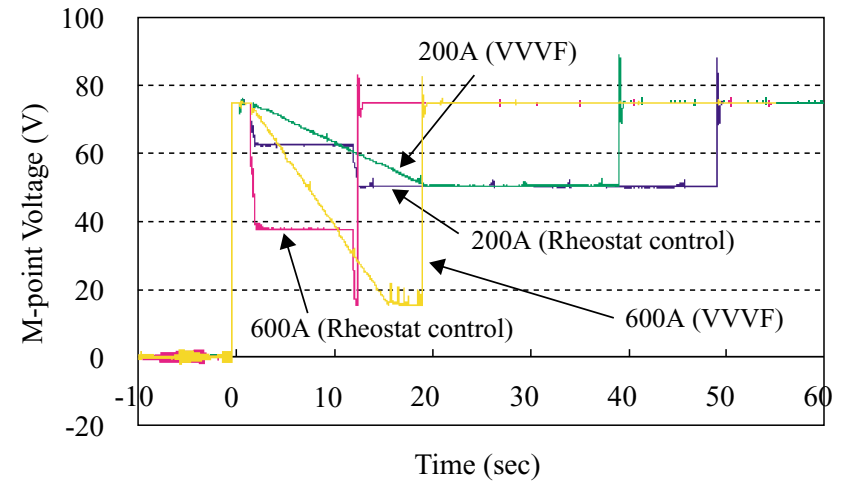

Fig. 4 DC 75V system M-point voltage characteristics

\subsubsection{Independent characteristics}

Next, tests were carried out to investigate independent charge/discharge characteristics of the three media. The peak current for all patterns was set at $600 \mathrm{~A}$.

(a) VVVF pattern

Test results using the VVVF pattern are shown in Figs. 5(a) and (b). The rated current capacity of the lithium battery used in the tests was lower than that of the lead battery. However, the discharge current from the former was larger and the voltage drop lower. The discharge current was dependent on the ratio of the resistance on the DC supply side and that of the storage media. Therefore, the discharge current from the EDLCs was lower than that of other media, because the inner

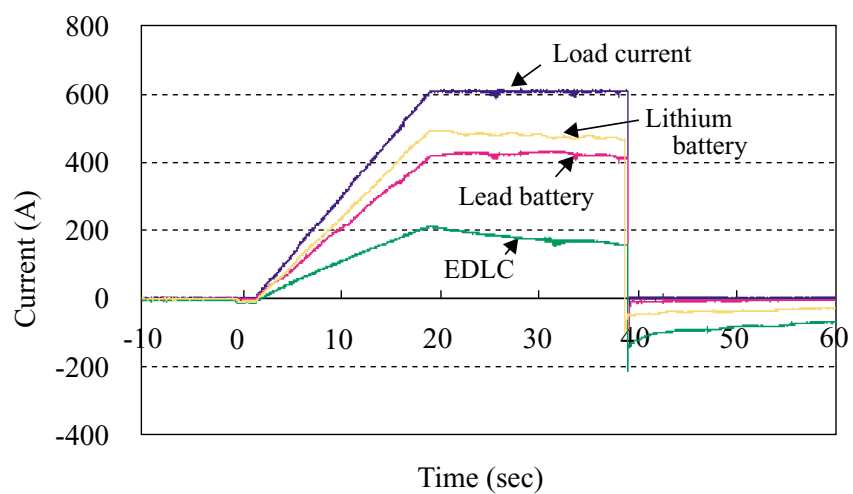

(a) Discharge current

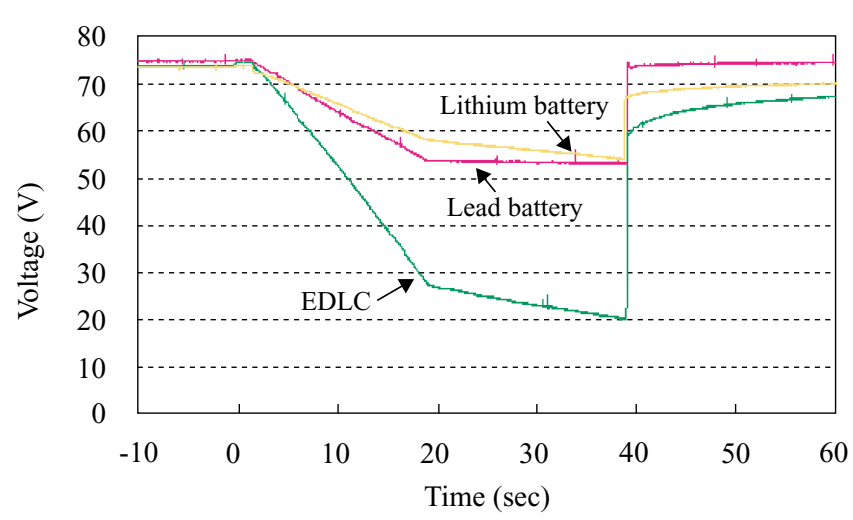

(b) Voltage at the M-point

Fig. 5 Independent characteristics (VVVF)

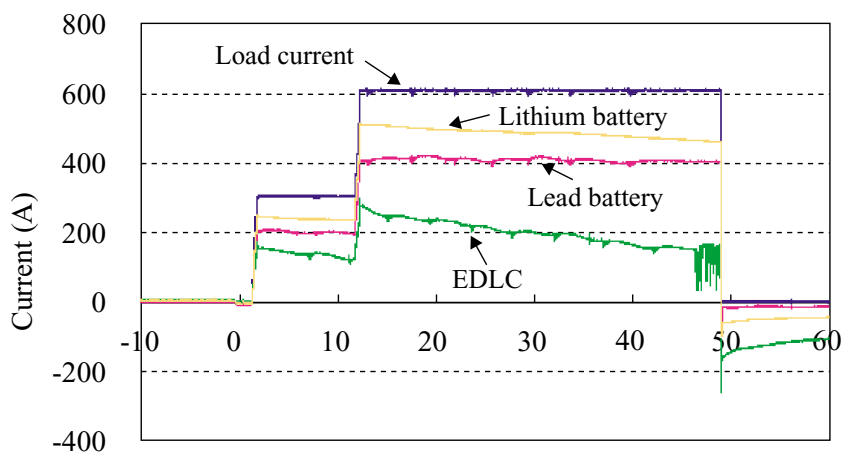

Time (sec)

(a) Discharge current

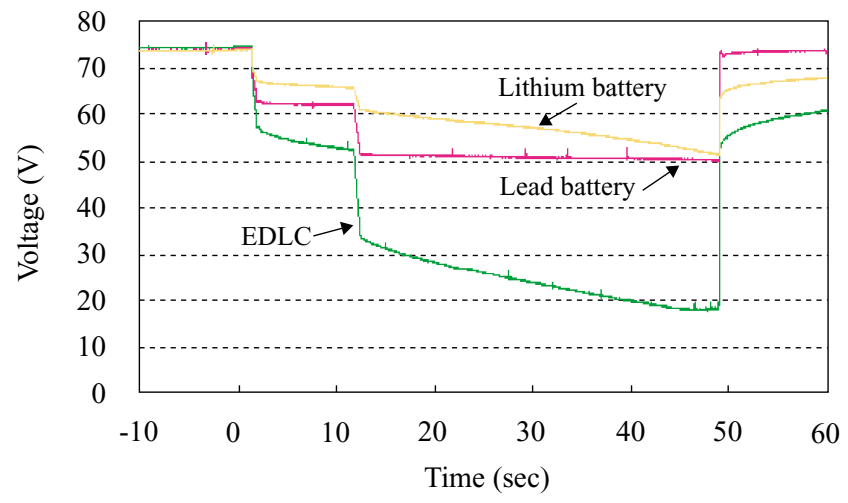

(b) Voltage at the M-point

Fig. 6 Independent characteristics (rheostat control)

resistance of the former is larger. Voltage is compensated for on account of discharge from the storage media. Therefore, it becomes possible to maintain the function of the load.

(b) Rheostat control pattern

Test results using the rheostat control pattern are shown in Figs. 6(a) and (b). When the load current was constant, the voltage of the lead battery hardly dropped, while that of the lithium battery or EDLCs dropped in proportion to time. The EDLC discharge current using this pattern was larger than that of the VVVF pattern when the load current changed.

\subsubsection{Hybrid characteristics}

From the above test results, the discharge current from EDLCs is much lower than that from the lithium battery, and the waveform of the former resembles that of the latter. Therefore, it is anticipated that a hybrid energy storage system combining EDLCs and a lithium battery would not have more effective characteristics than those obtained by applying the latter only. On the other hand, the discharge current obtained from the lead battery indicated different characteristics. Therefore, charge/discharge tests were carried out using EDLCs and a lead battery connected in parallel, test results from this hybrid system being shown in Figs. 7(a)-(c). The peak current was again set at 600A. From the result in Fig. 7(a), the battery discharge current was about three times that from the EDLCs because of the influence of 


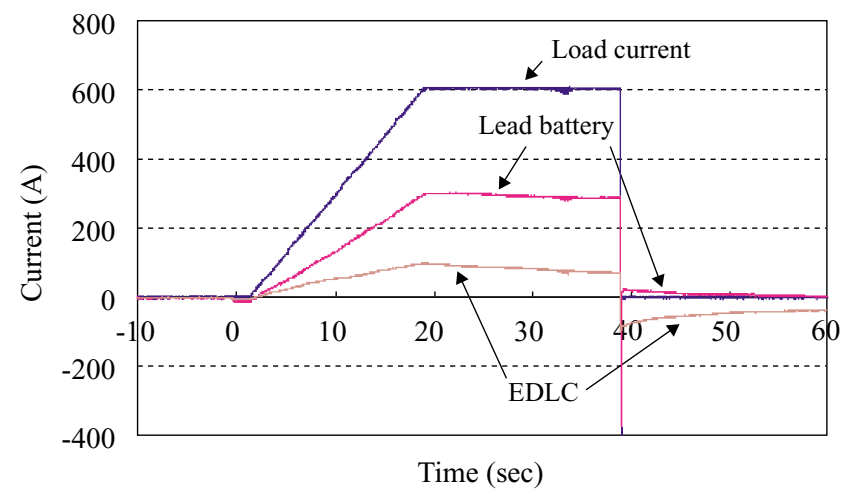

(a) Discharge current (VVVF pattern)

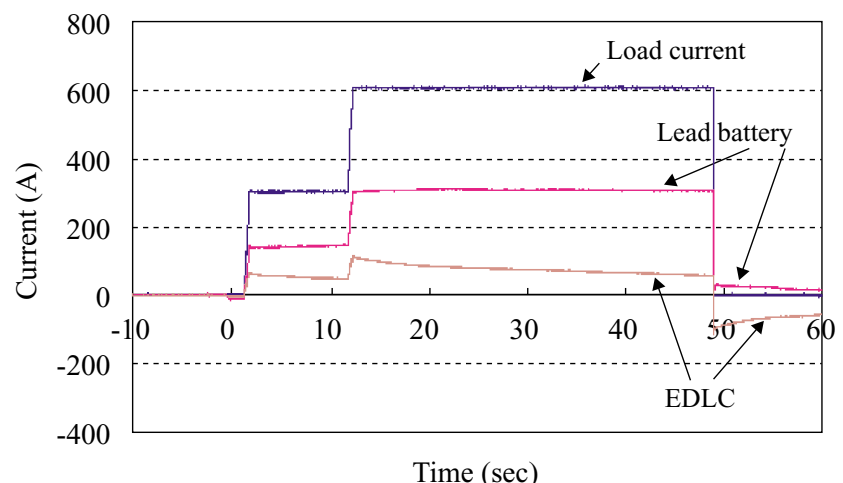

(b) Discharge current (rheostat control pattern)

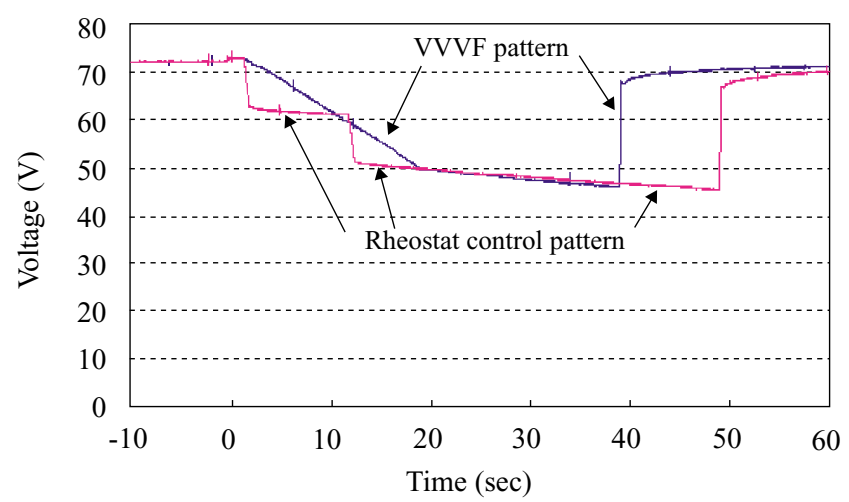

(c) Voltage at the M-point

Fig. 7 Hybrid characteristics

each inner resistance. Figure 7(b) shows that the discharge current from the EDLCs was about half that of the battery when the load current increased steeply. After that, the ratio of discharge current from the battery continued to increase. From Fig. 7(c), it is thought that the voltage drops in response to the characteristics of the EDLCs when the load current is constant.

\subsection{Consideration} lows.

Discussions in this chapter can be summarized as fol-

- Lead battery

Clear changes in voltage or discharge current are hardly shown at a constant load. Therefore, it is appropriate to compensate long-term DC voltage drops.
- Lithium battery

The inner resistance is smaller than that of other media and the starting discharge current larger. The discharge current decreases more over time when compared with that of a lead battery.

- EDLC

Because the energy density is less than that of batteries, drops in charged voltage and discharge current are larger. The starting discharge current is less due to inner resistance. When the load current increases steeply, however, the discharge current is comparatively large. Therefore, it is appropriate to use EDLC if the load pattern is like that under rheostat control.

- Hybrid (applying a lead battery combined with EDLCs)

The ratio of discharge current is in inverse proportion to the ratio of inner resistance. Since discharge current from a lead battery is reduced, its life may be prolonged. On the other hand, direct effects such as compensating for DC voltage drops, cannot be expected with DC feeding systems. To obtain such favorable characteristics, it will be necessary to install a power conversion system between the battery and the EDLCs and regulate the charge/discharge operation.

\section{Energy storage prototype}

This chapter describes the composition of the prototype and test results.

\subsection{Main circuit}

Figure 8 shows the main circuit of the prototype. A set of inductance $(1 \mathrm{mH})$ and resistance $(0.04 \mathrm{ohm})$ is connected between the rectifier and the EDLCs, and another between the EDLCs and the PWM converter to simulate the feeding circuit constants. It is possible to simulate the real distances between a substation and a railway vehicle by changing their values. The EDLCs are installed between the substation and the railway vehicle.

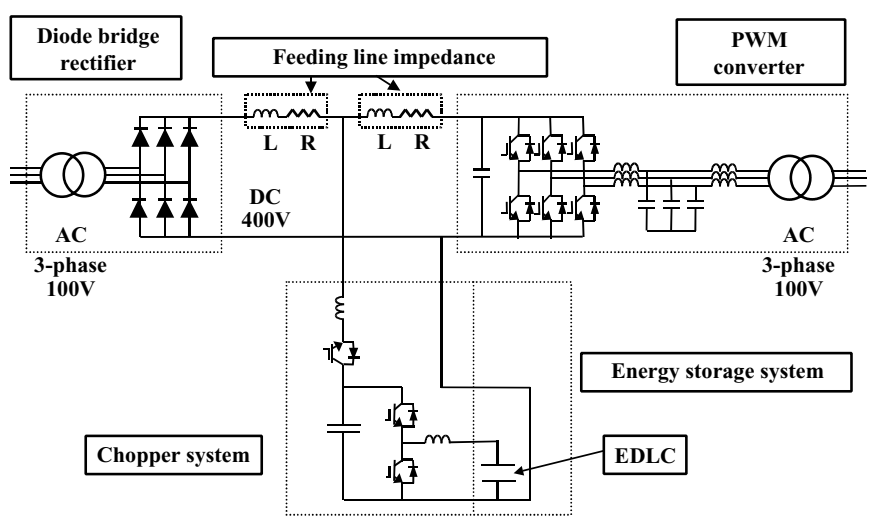

Fig. 8 Main circuit model

\subsection{EDLC module}

Table 3 sets out the EDLC specifications, and Fig. 9 shows an individual EDLC unit and the EDLC installation. 
Table 3 Composition of EDLCs for the prototype

\begin{tabular}{cccc}
\hline Item & Unit & Block & Module \\
\hline Composition & $\begin{array}{c}46 \text { cells } \\
\text { in series }\end{array}$ & $\begin{array}{c}8 \text { units } \\
\text { in parallel }\end{array}$ & $\begin{array}{c}3 \text { blocks } \\
\text { in series }\end{array}$ \\
\hline Voltage & $93 \mathrm{~V}$ & $93 \mathrm{~V}$ & $280 \mathrm{~V}$ \\
\hline Current & $50 \mathrm{~A}$ & $400 \mathrm{~A}$ & $400 \mathrm{~A}$ \\
\hline Capacity & $12 \mathrm{~F}$ & $97 \mathrm{~F}$ & $32 \mathrm{~F}$ \\
\hline Resistance & $0.44 \Omega$ & $0.05 \Omega$ & $0.16 \Omega$ \\
\hline \multirow{2}{*}{ Dimensions } & D 340 & D 431 & D 1000 \\
& W 340 & W 465 & W 900 \\
& H $50 \mathrm{~mm}$ & H 537 mm & H 2300 mm \\
\hline Weight & $7.2 \mathrm{~kg}$ & $74.5 \mathrm{~kg}$ & $715 \mathrm{~kg}$
\end{tabular}
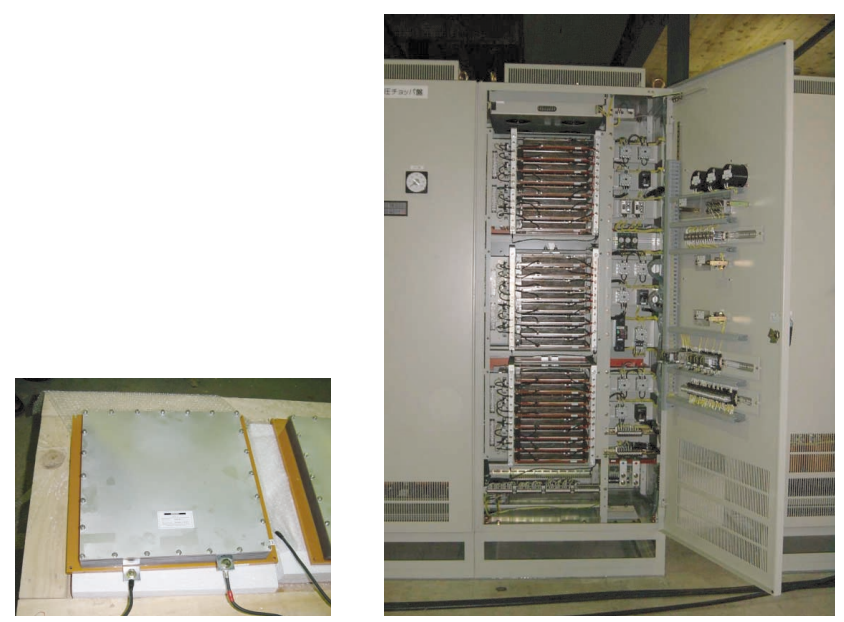

Fig. 9 EDLC unit and installation

Since the voltage per cell of an EDLC is $2 \mathrm{~V}$, we increased the voltage and capacity of the model by connecting cells in series and parallel, respectively. The energy capacity of the prototype is about $80 \mathrm{~kW}$ that is available for five seconds. This prototype was expected to be charged $1 / 10$ of the actual regenerative current.

\subsection{Diode rectifier}

A three-phase bridge diode rectifier simulates an electrified railway substation, converting three-phase AC 100 $\mathrm{V}$ into DC $400 \mathrm{~V}$. Transformer taps can regulate the DC voltage. The $\mathrm{DC}$ voltage at the $100 \%$ load current is regulated in the range of $8 \%$.

\subsection{PWM converter}

A PWM converter models railway vehicles as a load on the power system. It is operated as a DC current source at a constant voltage. The DC output current of PWM converter is controlled according to the current pattern. Regenerative power provided from railway vehicles is simulated when three-phase AC $100 \mathrm{~V}$ is changed into DC $400 \mathrm{~V}$ and the powering of railway vehicles is simulated when power is converted from DC to AC. It is also possible to input a load current model for actual railway vehicles.
1. Standby mode $: V_{c} \rightarrow$ Constant

2. Charge and discharge $: V_{s} \rightarrow$ Constant

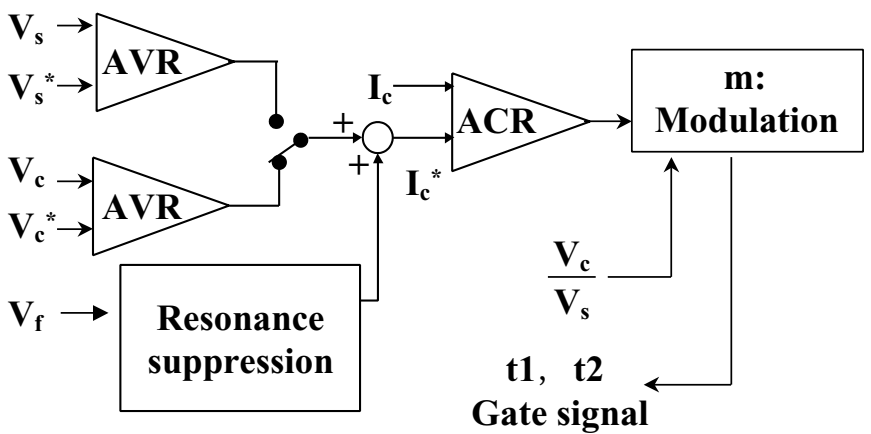

$V_{c}^{*}=$ EDLC voltage in standby mode

$\mathrm{V}_{\mathrm{s}}{ }^{*}=$ Maximum voltage in charge mode

Minimum voltage in discharge mode

Fig. 10 Diagram of chopper system

\subsection{Chopper system}

Figure 10 shows a diagram of the chopper system. The chopping frequency is $4 \mathrm{kHz}$. The chopper system has a bi-directional function. It works as a chopper to decrease voltage when it charges up the EDLCs, and to increase voltage when it discharges them. Switches are installed to prevent current from the EDLCs to the feeding line when a large drop in feeding voltage occurs, and an LC filter suppresses the switching component of chopper system. The operation of the chopper system is divided into three modes. In the initial charge mode, the EDLCs are charged with a constant current. In the discharge mode, the EDLCs are discharged when the feeding voltage drops below the set value. In the charge mode, the EDLCs are charged when the feeding voltage is higher than the set value. In addition, if the absolute value of feeding voltage is within the upper and lower set values, there is a standby mode that maintains EDLC voltage levels. By changing the feedback gain of the control circuit, it is possible to vary the scope of each part's resonance suppression.

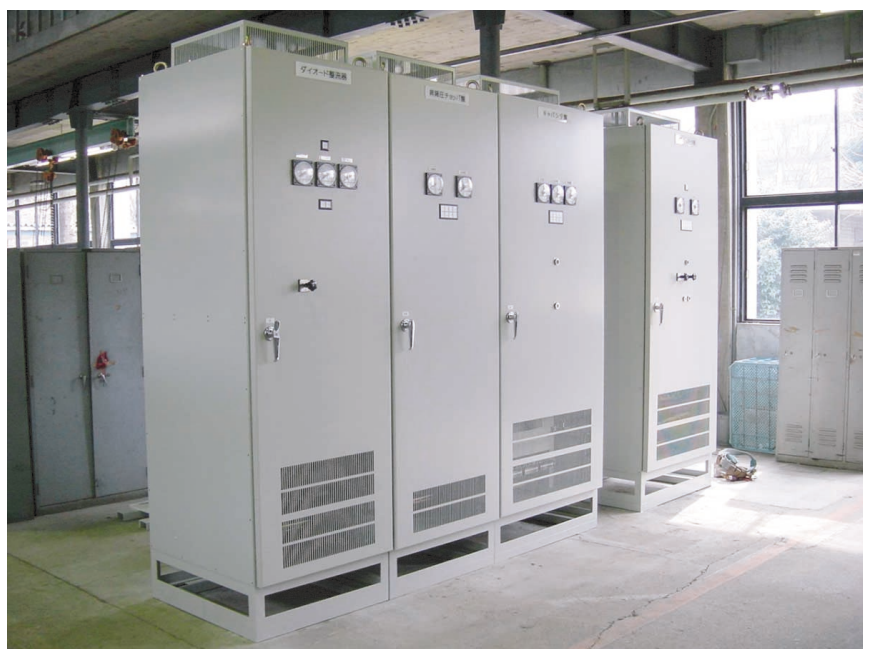

Fig. 11 Appearance of prototype 


\subsection{Appearance of the prototype}

Figure 11 shows the energy storage prototype produced as a trial. Seen from left to right are the diode bridge rectifier, the chopper system, the EDLCs, and the PWM converter.

\subsection{Test results}

Fundamental tests were carried out by setting the values of each part to the limits shown in Table 4 . The EDLCs were discharged at a chopper voltage less than $370 \mathrm{~V}$, and charged at over $416 \mathrm{~V}$, the charged/discharged current being less than $200 \mathrm{~A}$. The maximum voltage of the EDLCs was $270 \mathrm{~V}$, the minimum $120 \mathrm{~V}$. Therefore, the EDLCs could be discharged with $80 \%$ or more of charged energy.

The current waveform pattern shown in Fig. 12 applies to a PWM converter. This current was measured at an electrified railway substation for five minutes, where railway vehicles of the power regeneration type are operated.

Test results derived from this waveform pattern are shown in Fig. 13. These characteristics are summarized as follows.

(1) The rectifier current is equivalent to the PWM current without EDLCs. If EDLCs are installed, the EDLCs are discharged when the PWM current becomes high. Therefore, the peak of the rectifier current is reduced by about $70 \mathrm{~A}$.

(2) The EDLC can continue charging and discharging in this manner because the EDLC voltage reverts to the maximum through one charge/discharge pattern.

(3) When the PWM current is high, the PWM voltage normally decreases drastically. If EDLCs are installed, however, the EDLCs are discharged and the voltage drop due to the resistance of the feeding line is reduced. Therefore, the drop of the PWM voltage is

Table 4 Set values

\begin{tabular}{ccc}
\hline DC Voltage & & $400 \mathrm{~V}$ \\
\hline \multirow{2}{*}{ Chopper Voltage } & Max & $416 \mathrm{~V}$ \\
\cline { 2 - 3 } & Min & $370 \mathrm{~V}$ \\
\hline Initial Charged EDLC Voltage & $250 \mathrm{~V}$ \\
\hline \multirow{2}{*}{ EDLC Current } & Max & $200 \mathrm{~A}$ \\
\cline { 2 - 3 } & Min & $-200 \mathrm{~A}$ \\
\hline \multirow{2}{*}{ EDLC Voltage } & Max & $270 \mathrm{~V}$ \\
\cline { 2 - 3 } & Min & $120 \mathrm{~V}$ \\
\hline
\end{tabular}

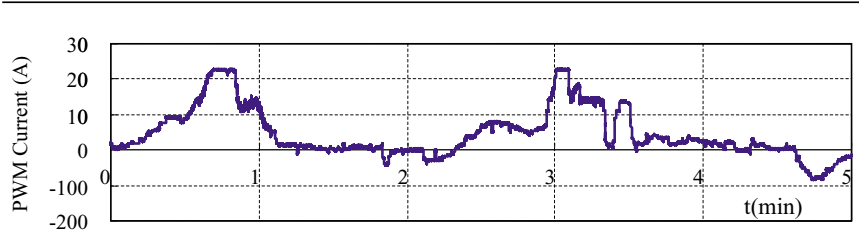

Fig. 12 PWM converter waveform pattern
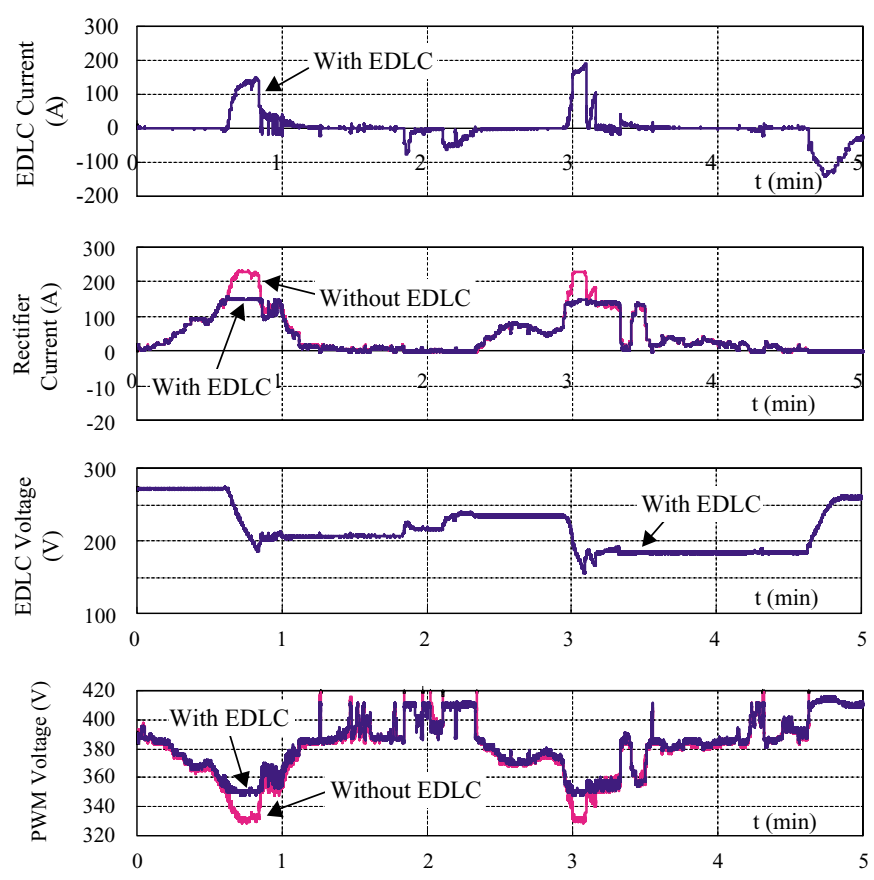

Fig. 13 Prototype test characteristics

also compensated for by about $20 \mathrm{~V}$.

\section{Conclusion}

Fundamental tests were carried out to clarify charge/ discharge characteristics of EDLCs and batteries, useful information being obtained from them. We produced an energy storage system by applying EDLCs as energy storage media and confirmed that an energy storage system of this type would provide an effective method to realize a more stable DC electric railway system. We now plan to focus our attention on practical energy storage applications on actual railway systems.

\section{References}

1) Spaeth, H., Becker, K-P.: European Transactions on Electrical Power, Proc. Energy Storage by Capacitors., Vol.12, No.3, 211-216 (2002).

2) Zubieta, L., Bonert, R.: Conference Record of the 1999 IEEE Industry Applications Conference, Proc. Experimental 400kWsec Double-layer Capacitor Energy Storage System., Vol.4, 2448-2553 (1999).

3) Zubieta, L., Bonert, R.: IEEE Transactions on Industry Applications, Proc. Characterization of DoubleLayer Capacitors for Power Electronics Applications., Vol.36, No.1, 199-205 (2000).

4) Hase, S., Konishi, T., Okui, A., Nakamichi, Y., Nara, H., and Uemura, T.:PCC-Osaka 2002, Proc. Fundamental Study on Energy Storage System for DC Electric Railway System., 1456-1459 (2002). 